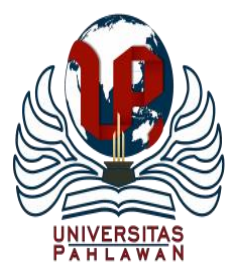

Jurnal Abdidas Volume 2 Nomor 1 Tahun 2021 Halaman 69-74

JURNAL ABDIDAS

http://abdidas.org/index.php/abdidas

\title{
Pelatihan dan Pendampingan Peningkatan Pangsa Pasar dengan Model Kepuasan Pengiriman Pesanan Konsumen Obat pada Apotek di Surakarta
}

\author{
Siti Fatonah ${ }^{1 凶}$, Lukman Ahmad Imron Pahlawi ${ }^{2}$, P. Haryoso ${ }^{3}$ \\ Magister Manajemen, STIE AUB Surakarta, Indonesia ${ }^{1,3}$ \\ Manajemen, STIE AUB Surakarta, Indonesia ${ }^{2}$ \\ E-mail : $\underline{\text { siti.fatonah@stie-aub.ac.id }} \underline{\text { imron.aub@stie-aub.ac.id }}^{2}$ i p.haryoso@stie-aub.ac.id ${ }^{3}$
}

\begin{abstract}
Abstrak
Salah satu faktor penting yang mempengaruhi berkembangnya suatu apotek yaitu bagaimana apotek dapat memberikan kemudahan kepada konsumen untuk memesan obat dan menerima barang (obat) dengan mudah, cepat, aman dan nyaman. Tim Pengabdian kepada Masyarakat STIE AUB Surakarta ingin mensosialisasikan dan melatih serta mendampingi untuk menciptakan model kepuasan konsumen obat melalui peningkatan kualitas pengiriman pesanan untuk memperluas pangsa pasar obat pada Keluarga Besar Apotek Se-Surakarta. Ukuran keberhasilan dari kegiatan Pengabdian Kepada Masyarakat ini dapat dilihat dari luaran yang berupa 1) survei apotek dalam peningkatan kualitas pengiriman pesanan, 2) terciptanya model-model pengiriman pesanan, 3) pangsa pasar apotek bertambah. Permasalahan yang dihadapi oleh mitra adalah 1) belum maksimalnya kualitas pengiriman pesanan obat, 2) belum ada inovasi-inovasi dalam model-model pengiriman, 3) pangsa pasar masih terbatas. Tahapan pelaksanaan pengabdian yang sudah dilakukan oleh tim yaitu mensosialisasikan kepada masyarakat kemudahan dalam proses pemesanan serta pengiriman obat di apotek se-Surakarta, melatih mitra/apotek dalam menciptakan model-model pengiriman pesanan dan melatih teori manajemen pemasaran kepada mitra agar pangsa pasar lebih luas. Hasil yang diharapkan oleh tim adalah meningkatnya kepuasan konsumen apotek dan menciptakan loyalitas. Pada tahap selanjutnya adalah evaluasi hasil pendampingan kualitas pengiriman, model pengiriman dan perluasan pangsa pasar apotek.
\end{abstract}

Kata kunci: kualitas, model pengiriman pesanan, pangsa pasar

\section{Abstract}

One of the factors influencing a pharmacy is that how the pharmacy can provide consumers to order drugs and receive goods easily, quickly, safely and comfortably. The Community Service Team of STIE AUB Surakarta wants to socialize and train and assist to create a drug consumer satisfaction model through improving the quality of order delivery to expand the drug market in large family pharmacies in Surakarta. The size of this Community Service activity can be seen from the output in the form of 1) Pharmacy survey in improving the quality of order delivery, 2) creation of order delivery models, 3) increased pharmacy market supply. The problems that arise by partners are 1) the quality of drug order delivery has not been maximized, 2) there are no innovations in delivery models, 3) the market is still limited. The stages of the implementation of the service carried out by the team are socializing to the community in the process of ordering and sending drugs at pharmacies in Surakarta, training partners / pharmacies in creating order delivery models and training marketing management theories to partners in order to innovate wider markets. The results expected by the team are customer satisfaction and loyalty. The next stage is the evaluation of the results of quality delivery assistance, delivery models and expansion of the pharmacy market.

Keywords: quality, order delivery model, market share

Copyright (c) 2021 Siti Fatonah, Lukman Ahmad Imron Pahlawi, P. Haryoso

$\triangle$ Corresponding author

Address : Mojosongo, Surakarta

Email : siti.fatonah@stie-aub.ac.id

ISSN 2721- 9224 (Media Cetak)

DOI : https://doi.org/10.31004/abdidas.v2i1.214

ISSN 2721- 9216 (Media Online) 


\section{PENDAHULUAN}

Apotek merupakan garis terdepan dari rantai pasok industri farmasi yang dikenal olah masyarakat luas. Di Indonesia, lebih dari $24 \%$ obat yang diproduksi oleh industri farmasi didistribusikan di apotek (Rachmandani, A, Sampurno, dan Purnomo, P, 2011). Pertumbuhan jumlah apotek tiap tahun juga makin pesat. Hal ini disebabkan karena semakin besarnya jumlah penduduk Indonesia dan masalah kesehatan yang semakin kompleks.

Pelayanan farmasi di apotek saat ini telah bergeser dari pelayanan produk atau obat (drug oriented) menjadi pelayan pasien (patient oriented) (Purwanti A, Harianto, Supardi S, 2004). Kegiatan pelayanan yang tadinya hanya berfokus pada pengelolaan obat sebagai komoditi berubah menjadi pelayanan yang komprehensif dengan tujuan untuk meningkatkan kualitas hidup pasien.

Fenomena ini bisa dilihat pada transaksi obat di apotek, apotek tidak hanya melayani resep, namum juga menjual obat secara langsung kepada masyarakat yang membutuhkan bahkan di beberapa apotek ada pegawainya berprofesi sebagai dokter prakter pada apotek tersebut.

Keberlangsungan bisnis apotek salah satunya ditentukan oleh kepuasan konsumen. Kepuasan konsumen berkaitan erat dengan kualitas pelayanan. Kepuasan konsumen didapatkan jika apa yang dirasakan konsumen dari suatu pelayanan sebanding atau lebih besar dari harapan mereka (Kotler dan Keller, 2012). Pelayanan obat yang tepat dan berkinerja baik akan berpengaruh terhadap peningkatan kesehatan mayarakat yang utuh. Masyarakat pun semakin kritis memilih pelayanan farmasi. Apabila pelayanan berkualitas maka akan terwujud pula masyarakat yang berkualitas. pelayanan yang berkualitas artinya secara coorporate bisa memenuhi harapan konsumen.

Apotek di Surakata berkembang sangat pesat, melayani berbagai pesanan obat untuk kesembuhan penyakit yang diderita masyarakat. Berbagai inovasi dalam penyediaan dan modelmodel pengiriman obat perlu dilakukan oleh apotek agar kepuasan konsumen dapat dipenuhi sehingga loyalitas konsumen dapat meningkat. Kecenderungan apotek di Surakarta yang hanya menunggu konsumen datang ke Apotek memesan obat dan kualitas pengiriman pesanan yang belum maksimal adalah contoh faktor yang menyebabkan pangsa pasar menjadi tidak luas, untuk itu perlunya diadakan sosialisasi terhadap apotek pentingnya menjemput bola dalam memasarkan produk apotek sehingga memberi kemudahan kepada konsumen dalam memesan obat di apotek.

Atas dasar hal tersebut di atas Tim Pengabdian kepada Masyarakat STIE AUB Surakarta ingin mensosialisasikan dan melatih serta mendampingi untuk menciptakan model kepuasan konsumen obat melalui peningkatan kualitas pengiriman pesanan untuk memperluas pangsa pasar obat pada keluarga besar apotek SseSurakarta.

Tiga masalah utama yang dihadapi mitra dan komitmen antara mitra dengan tim, yaitu:

1. Belum maksimalnya kualitas pengiriman pesanan obat. Keterbatasan ini dilator- 
71 Pelatihan dan Pendampingan Peningkatan Pangsa Pasar dengan Model Kepuasan Pengiriman Pesanan Konsumen Obat pada Apotek di Surakarta - Siti Fatonah, Lukman Ahmad Imron Pahlawi, P. Haryoso

DOI: https://doi.org/10.31004/abdidas.v2i1.214

belakangi oleh belum maksimalnya layanan call center apotek dalam melayani konsumen serta belum tepat waktunya pengiriman obat kepada konsumen.

2. Belum ada inovasi-inovasi dalam modelmodel pengiriman. Model-model pengiriman pada masa sekarang ini sangatlah berinovatif, kecenderungan apotek hanya menunggu konsumen yang datang untuk membeli obat, sehingga dibutuhkan pelatihan atau pendampingan dalam menciptakan modelmodel pengiriman yang dapat dilakukan oleh mitra.

3. Pangsa pasar masih terbatas. Hal ini disebabkan kurangnya promosi yang dilakukan oleh apotek sehingga calon konsumen tidak mengetahui keunggulan apotek tersebut dalam melayani kebutuhan konsumen.

\section{METODE}

Kerangka pemecahan masalah untuk mengatasi permasalahan-permasalahan mitra yaitu agar meningkatnya kualitas pengiriman pesanan, terciptanya model-model pengiriman dan pangsa pasar dapat meningkat secara ringkas dapat di jelaskan dalam 5 tahapan sebagai berikut:

1. Dalam mengatasi masalah, tim melakukan koordinasi dengan mitra untuk merumuskan masalah, tujuan, sasaran dan materi kegiatan pengabdian kepada masyarakat.

2. Melaksanakan kegiatan sosialisasi tentang materi kualitas pengiriman pesanan, modelmodel pengiriman serta materi metode dalam meningkatkan pangsa pasar.
3. Melaksanakan pelatihan, pendampingan dan diskusi tentang kualitas pengiriman pesanan, model-model pengiriman serta materi metode dalam meningkatkan pangsa pasar yang telah dilaksanakan.

4. Melaksanakan evaluasi dan monitoring terhadap kegiatan mitra yang telah dilakukan.

5. Penyusunan laporan kegiatan pengabdian kepada masyarakat dan penulisan artikel kegiatan.

\section{HASIL DAN PEMBAHASAN}

Kegiatan pengabdian kepada masyarakat yang dilakukan oleh tim bersama mitra/apotek dapat dikatakan berhasil dan mampu memberi manfaat untuk mitra dalam upaya mencari solusi dalam permasalahan yang dihadapi. Ukuran yang merupakan indikator keberhsilan kegiatan pengabdian kepada masyarakat ini dapat diukur dari beberapa hal yaitu:

1. Sejak diadakan rencana kegiatan pengabdian kepada masyarakat ini antusias mitra dan masyarakat mengikuti sosialisasi, pelatihan, diskusi dan pendampingan tentang apotek. Hal ini nampak dari jumlah kehadiran semua mitra hadir dan mengikuti kegiatan dengan semangat.

2. Dalam pelaksanaan kegiatan ini semua peserta memiliki kesempatan untuk menyampaikan pendapatnya terkait dengan materi yang telah disampaikan oleh tim pengabdian kepada masyarakat. Sehingga terjadi tukar menukar ide dan gagasan dalam mengatasi permasalahan mitra. 
Pesanan Konsumen Obat pada Apotek di Surakarta - Siti Fatonah, Lukman Ahmad Imron Pahlawi, P. Haryoso

DOI: https://doi.org/10.31004/abdidas.v2i1.214

3. Dengan adanya kegiatan ini masyarakat yang diundang memiliki wawasan yang luas terkait pemilihan apotek sebagai tempat untuk membeli opat yang tepat di Surakarta.

Hasil monitoring dan evaluasi kegiatan pengabdian kepada masyarakat oleh tim ternyata menunjukkan bahwa ada peningkatan kualitas pengiriman obat, strategi memilih model pengiriman yang tepat dan pangsa pasar apotek lebih meningkat. Oleh karena itu kegiatan ini dapat dilanjutkan dimasa yang akan datang dengan melibatkan ahli yang lebih kompeten di bidang bisnis apotek ini.
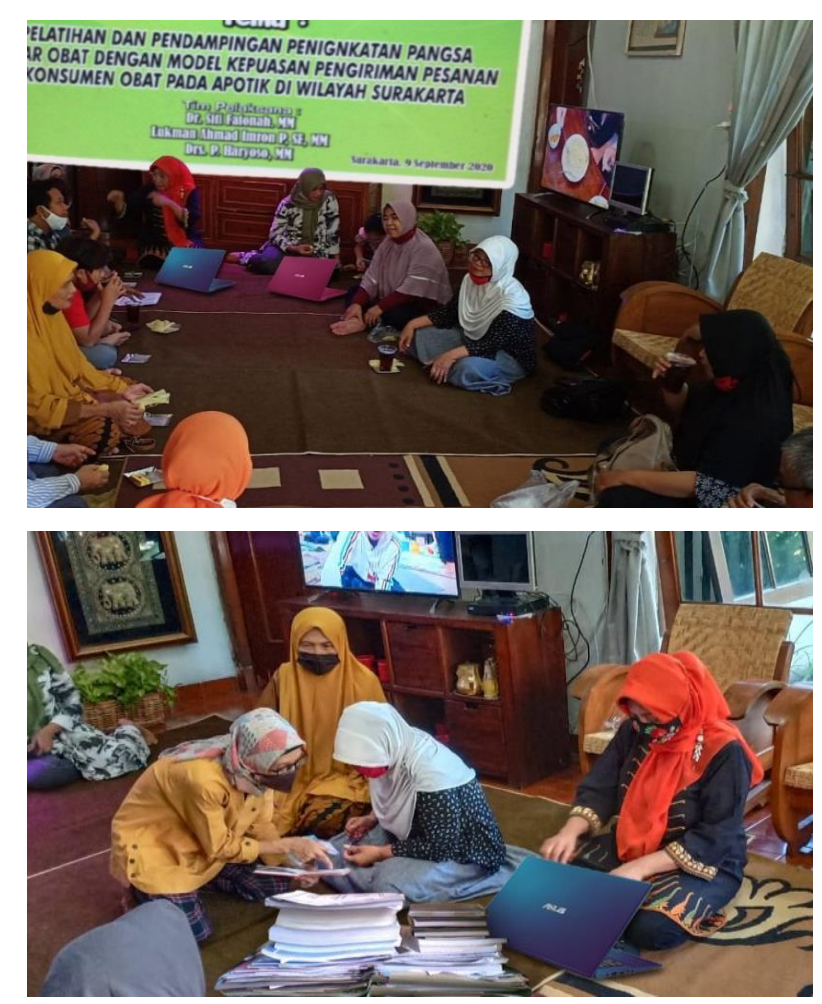

Gambar 1. Dokumentasi Kegiatan

Hasil kegiatan yang diperoleh dari kegiatan pengabdian kepada masyarakat dengan mitra dalam hal ini adalah apotek di Surakarta yaitu:
1. Kegiatan sosialisasi yang dilakukan bersama dengan mitra/apotek serta masyarakat mempunyai beberapa dampak hasil yang positif yaitu:

a. Mitra mengetahui dan memahami pentingnya kegiatan sosialisasi pemasaran produknya kepada masyarakat, adanya sosialisasi memperkenalkan produknya sehingga minat beli masyarakat menjadi meningkat.

b. Masyarakat lebih yakin dalam memilih apotek yang menyediakan obat untuk kebutuhannya.

2. Dampak kegiatan pengabdian kepada masyarakat ini dalam mengatasi permasalahan mitra tentang kualitas pengiriman yaitu mitra mengetahui dan memahami beberapa hal sebagai berikut:

a. Layanan call center pengiriman pesanan belum mudah untuk dihubungi oleh konsumen sehingga menyebabkan konsumen tidak merasa puas dalam pengiriman pesanan.

b. Kualitas sikap petugas call center pengiriman pesanan dalam menerima pesanan, keluhan maupun saran dari konsumen pemesanan perlu ditingkatkan.

c. Pengepakan pesanan obat lebih ditingkatkan kerapian dan keamanan pesanan obat itu agar pada saaat diterima oleh konsumen tidak rusak.

d. Waktu pengiriman pesanan saat diterima oleh konsumen tepat waktu sangatlah penting untuk memenuhi kepuasan 


\section{konsumen.}

3. Dampak kegiatan pengabdian kepada masyarakat ini dalam mengatasi permasalahan mitra tentang model-model pengiriman pesanan sebagai berikut:

a. Mitra mengetahui banyak pilihan model pengiriman pesanan selain menggunakan layanan call center apotek. Diantaranya menggunakan aplikasi pengiriman pesanan yang telah tersedia pada handphone.

b. Mitra dapat menentukan strategi dalam memilih model pengiriman pesanan sesuai dengan kebutuhan konsumennya.

4. Dampak kegiatan pengabdian kepada masyarakat ini dalam mengatasi permasalahan mitra tentang meningkatkan pangsa pasar sebagai berikut:

a. Penataan layout dan display penataan obat di apotek mempengaruhi minat datang dan beli masyarakat sehingga perlu ditata untuk menarik masyarakat beli diapotek.

b. Identitas apotek perlu ditonjolkan dalam pembuatan baliho dan leaflet apotek.

c. Menentukan alat promosi yang tepat dalam upaya menarik minat konsumen baru.

d. Menentukan harga obat agar lebih menjual dan menarik minat beli konsumen, dalam arti mengambil untung relatif kecil namun konsumen yang tertarik banyak.

e. Apotek mengadakan pengobatan gratis untuk menjari konsumen baru.

\section{SIMPULAN}

Hasil kegiatan pengabdian kepada masyarakat STIE AUB Surakarta bagi mitra memberikan manfaat yang besar dalam mengatasi permasalahan yang dihadapi oleh mitra, yaitu tentang kualitas pengiriman, model pengiriman serta pangsa pasar. Mitra perlu mengembangkan ide-ide bisnis dalam membangun usaha yang telah dirintis. Dengan kegiatan sosialisasi, pelatihan, diskusi dan pendampingan akan sangat memberikan manfaat bagi mitra dalam mengembangkan usahanya. Materi kegiatan pengabdian kepada masyarakat bagi mitra ini menekankan pada strategi kualitas pengiriman produk, model pengiriman serta strategi meningkatkan pangsa pasar. Hal ini sangat bermanfaat bagi mitra untuk membangun usaha yang ada.

Keberhasilan program kegiatan pengabdian kepada masyarakat ini sangat dipengaruhi oleh beberapa faktor yaitu 1) dukungan penuh dari STIE AUB Surakarta dalam menyediakan dana kegiatan ini, 2) minat mitra yang sangat tinggi dalam kegiatan ini, 3) masyarakat membutuhkan informasi yang jelas untuk memilih apotek sesuai dengan kebutuhannya

\section{UCAPAN TERIMA KASIH}

Terima kasih kepada P3M STIE AUB Surakarta dan lembaga STIE AUB Surakarta yang telah memberikan kesempatan dan ijin untuk terselenggaranya kegiatan Pengabdian Kepada Masyarakat ini, tidak lupa seluruh peserta Pengabdian Kepada Masyarakat yang telah ikut 
74 Pelatihan dan Pendampingan Peningkatan Pangsa Pasar dengan Model Kepuasan Pengiriman Pesanan Konsumen Obat pada Apotek di Surakarta - Siti Fatonah, Lukman Ahmad Imron Pahlawi, P. Haryoso

DOI: https://doi.org/10.31004/abdidas.v2i1.214

berpartisipasi dalam kegiatan ini sehingga kegiatan

Pengabdian Kepada Masyarakat dapat berjalan dengan lancar.

\section{DAFTAR PUSTAKA}

AA. Anwar Prabu Mangkunegara, 2013, Manajemen Sumber Daya Manusia Perusahaan, Remaja Rosdakarya, Bandung

R Edy, Sutrisno, (2016), Manajemen Sumber Daya Manusia, Kencana Prenada Media Group, Jakarta

Kotler,Philip, Kevin L. Keller 2012, Marketing Management. 13th edition, New Jersey : Pearson Prentice Hall, Inc

Peraturan Menteri Kesehatan RI nomor 35 tahun 2014 tentang Standar Pelayanan Kefarmasian Di Apotek

Purwanti A, Harianto, Supardi S, 2004, Gambaran Pelaksanaan Standar Pelayanan Farmasi di Apotek DKI Jakarta Tahun 2003, Majalah Ilmu Kefarmasian Vol.1 No.2, (online), (http://jurnal.farmasi.ui.ac.id/pdf/2004/ v01n02/angki010205.pdf)

Rachmandani, A, Sampurno, dan Purnomo, P. 2011. Peran Ikatan Apoteker Indonesia (IAI) Dalam Upaya Pelaksanaan Standar Pelayanan Kefarmasian Di Apotek Di Daerah Istimewa Yogyakarta. Jurnal manajemen dan pelayanan Farmasi. Yogyakarta 